\title{
Louis-Philippe Dalembert, Un tambour pour les anges
}

\section{Alba Pessini}

\section{(2) OpenEdition}

\section{Journals}

\section{Édition électronique}

URL : https://journals.openedition.org/studifrancesi/39887

DOI : $10.4000 /$ studifrancesi.39887

ISSN : 2427-5856

\section{Éditeur}

Rosenberg \& Sellier

\section{Édition imprimée}

Date de publication : 1 décembre 2004

Pagination : 420

ISSN : 0039-2944

\section{Référence électronique}

Alba Pessini, «Louis-Philippe Dalembert, Un tambour pour les anges », Studi Francesi [En ligne], 143 (XLVIII | II) | 2004, mis en ligne le 30 novembre 2015, consulté le 19 mai 2021. URL : http:// journals.openedition.org/studifrancesi/39887 ; DOI : https://doi.org/10.4000/studifrancesi.39887

Ce document a été généré automatiquement le 19 mai 2021.

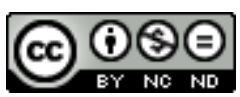

Studi Francesi è distribuita con Licenza Creative Commons Attribuzione - Non commerciale - Non opere derivate 4.0 Internazionale. 


\title{
Louis-Philippe Dalembert, Un tambour pour les anges
}

\author{
Alba Pessini
}

\section{RÉFÉRENCE}

LOUIS-PHILIPPE DALEMBERT, Un tambour pour les anges, récit (photos de David Damoison et préface de Laënnec Hurbon), Paris, Autrement, 2003, pp. 159.

Deux plumes (celle du chercheur au CNRS Laënnec Hurbon et du romancier LouisPhilippe Dalembert) et un objectif (celui de David Damoison) tentent dans cet ouvrage de sonder et de dévoiler les mystères d'un culte par trop méconnu, discrédité et souvent relégué, dès le XVII ${ }^{e}$ siècle par les premiers voyageurs, au rang de sorcellerie. Laënnec Hurbon, anthropologue et auteur de plusieurs ouvrages de référence sur le vodou, nous convie à remonter aux origines de ce culte, à en reconstruire la généalogie et nous montre comment il fut pour l'esclave, lors de la période coloniale, un moyen pour la "reconstruction d'un espace et d'un temps" qui lui fut propre par rapport à celui du maître, la recherche d'une identité non seulement individuelle mais aussi collective et une croyance où puiser la foi pour une libération future. $\mathrm{Au} \mathrm{XX}^{\mathrm{e}}$ siècle, selon Hurbon, la méfiance face à cette religion semble baisser quelque peu les armes surtout grâce à Price Mars et à des auteurs qui se questionnent sur son fonctionnement. La littérature aussi lui ouvre ses portes. Hurbon se penche sur la période duvaliériste et sur la connivence entre vodou et politique, cette dernière s'alliant officiellement avec le culte catholique tout en n'oubliant pas de servir, mais cette fois-ci de façon plus cachée, les dieux du panthéon vodou, une occasion aussi de surveiller et de s'attirer la sympathie des vodouisants. Dans la dernière partie de la préface, Hurbon plonge le lecteur au cœur même de cette religion en l'introduisant à ses rites, à ses dieux et à ses adeptes, aux rapports qui se tissent entre loas et vodouisants. La conclusion de l'anthropologue, en ces temps d'extrémisme et d'intégrisme qui accompagnent les 
religions, souligne l'aspect de tolérance qui anime le vodou face aux "autres systèmes religieux dont il intègre volontiers maints éléments".

2 La fiction de Louis Philippe Dalembert, aux saveurs autobiographiques, nous entraîne elle aussi à la découverte du vodou. Le protagoniste, un Salboundais (Salbounda est l'île de fiction que l'auteur a créé dans son premier roman Le Crayon du Bon Dieu n'a pas de gomme, mais il s'agit en réalité d'Haïti) de passage à New York, assiste pour la première fois, grâce à son amie C..., à une cérémonie vodou. Cette première initiation tardive ne peut qu'étonner si l'on tient compte de ses origines. La méconnaissance de ce culte est à reconduire à son enfance où le vodou était marqué du sceau de l'interdit. Grannie, sa grand-mère qui l'a élevé, a toujours refusé, tout en ayant été initiée, de fréquenter les péristyles, les cérémonies et la cour Blain: lieu mystérieux et attirant s'il en est pour l'enfant qui ne connaît de cet espace que les bruits qui s'en échappent et les quelques informations captées au gré des conversations des adultes ou directement rapportées par ses amis. Grannie défend donc à l'enfant d'avoir affaire de près ou de loin avec ces "satanneries" qui pourraient lui valoir le redoutable martinet B12. Pourtant, la curiosité mêlée à la crainte que suscite en lui le vodou et ce qui s'y rattache, le poussent à désobéir. C'est dans le "spectacle" de la transe de Marie, une jeune domestique, possédée par un loa (les commentaires du voisinage à cet égard ne sont pas unanimes: possession ou simple exhibition...) qu'il est initié aux plaisirs des sens; caché sous la table de la cuisine d'un voisin, il assiste, plein d'effroi, au retour en Guinée du père d'un de ses amis, moment solennel du vodou auquel peu d'individus sont conviés, sans pouvoir en toucher mot à personne de peur d'une punition exemplaire de Grannie. Les anecdotes se succèdent et le voient tantôt témoin de la guérison de ton'Wilson de la main même de Grannie qui, pour le bien d'autrui, peut déroger à ses règles, tantôt protagoniste d'un geste fou, réveiller les loas en plein midi au son du tambour qu'il frappe, fasciné par le rythme qu'il émet. La nouvelle se boucle comme elle avait commencé à New York dans l'appartement de C... qui ne cache pas son regret, sa difficulté à comprendre l'un des rares Salboundais ayant déserté le vodou.

3 Ces deux écrits sont accompagnés à la fin du volume par des photos en noir et blanc de David Damoison qui nous entraînent dans les lieux de la tradition vodou, de Souvenance à Ville-Bonheur, du bassin Saint-Jacques à Saut d'eau en passant par quelques péristyles d'Haïti ou d'ailleurs et qui clouent notre regard sur un monde inconnu qui se dévoile à nous dans toute la force de ces images. Les trois points de vue n'ont en rien l'effet d'un simple collage mais se complètent, se mêlent, pour conduire le lecteur à une vision plus profonde et dépourvue de l'entrave du cliché et du stéréotype. 